\title{
Tadalafil protector effect during ischemia-reperfusion in rats ${ }^{1}$
}

Eduardo Gabriel Gerber Wietzikoski', Julio Cesar Foiatto', Nicolau Gregori Czeczko", Osvaldo Malafaia", Fernando Cesar Koleski"', Tiago Cesar Mierzwa"v, Regina de Paula Xavier Gomes ${ }^{v}$

'Fellow Master degree, Postgraduate Program in Surgery Principles, Medical Research Institute, Faculdade Evangélica do Paraná (FEPAR), Curitiba-PR, Brazil. Conception, design, intellectual and scientific content of the study; manuscript preparation.

"Associate Professor, Postgraduate Program in Principles of Surgery, Medical Research Institute, FEPAR, Curitiba-PR, Brazil. Intellectual and scientific content of the study, interpretation of data, critical revision.

"'MD, Department of Urology, Hospital Nossa Senhora das Graças, Curitiba-PR, Brazil. Manuscript preparation.

${ }^{I V}$ Resident, Hospital Nossa Senhora das Graças, Curitiba-PR, Brazil. Manuscript preparation.

${ }^{\vee}$ PhD, Department of Pathology, Universidade Federal do Paraná (UFPR), Curitiba-PR, Brazil. Histopathological examinations.

\begin{abstract}
Purpose: To evaluate histological parameters in rat renal tissue after tadalafil use during hot ischemia for 45 minutes and reperfusion for 24 hours.

Methods: Twenty rats were divided into 2 groups. In the experimental group $10 \mathrm{mg} /$ $\mathrm{kg}$ of tadalafil was used per gavage before the procedure. All cases underwent left partial nephrectomy, followed by 45 minutes of warm ischemia. Left nephrectomy of the remaining kidney was performed after 24 hours from the initial procedure. The histological parameters analyzed were: detachment of tubular cells, accumulation of desquamated cells in the proximal tubule, loss of brush border, tubular cylinders, interstitial edema, leukocyte infiltration, capillary congestion, vacuolization, tubular dilatation, necrosis and collapse of the capillary tuft.

Results: Two rats from each group died and were excluded from the study. Tadalafil significantly reduced leukocyte infiltration $(p=0.036)$. The remaining histological parameters did not show statistical difference between the groups.

Conclusion: The use of tadalafil during warm ischemia and reperfusion demonstrates statistically significant reduction of leukocyte infiltration in the renal interstitium.

Key words: Tadalafil. Reperfusion Injury. Ischemia. Kidney. Rats.
\end{abstract}




\section{Introduction}

Cell injury occurs according to several degrees after procedures that cause interruption of blood flow and temporary ischemia of the kidney. The clinical manifestations of cell injury, such as renal failure, may have high morbidity and mortality rates. Cardiac, aortic, partial nephrectomy, and renal transplantation may lead to renal cell damage both in the ischemic period or during reperfusion. In partial nephrectomies, where the aim of the procedure is the removal of the tumor with the maximum preservation of the renal parenchyma, various degrees of damage to the healthy parenchyma occur, especially in prolonged surgeries. During the partial nephrectomy procedure, it is necessary to interrupt blood flow to the kidney in order to reduce intraoperative bleeding and increase the safety of the procedure, leading to a temporary renal tissue ischemia ${ }^{1}$.

With the advent of laparoscopic partial nephrectomy as a gold standard method for treatment of renal tumors, hypothermia, that was routinely used in open surgeries to increase the period of ischemia, is no longer performed due to technical aspects. A period of 20 to 30 minutes of warm ischemia is considered safe for performing the procedure without repercussion to the functioning of the kidney, which makes the preservation of renal cells challenging in surgery of greater technical difficulty ${ }^{2}$.

The kidney damage process involves complex sequences that are present in both ischemia and reperfusion periods. The binomial ischemia-reperfusion (I / R) causes vasoconstriction, tubular edema, tubular epithelium necrosis, endothelial injury, leukocyte activation, free radical production and mitochondrial dysfunction. Cell injury begins immediately after renal ischemia is established ${ }^{3}$.

During the cascade of events that occurs in the I/ R, nitric oxide (NO) has a central action.
Their levels increase in the period of ischemia, acting as inhibitor of platelet aggregation, thus preventing renal microcirculation thrombosis during reperfusion. It also acts as a stabilizer of the endothelial membrane against free radicals, blocking monocyte activation, decreasing leukocyte infiltration, and having a direct vasodilator effect in the microcirculation during the reperfusion period ${ }^{4}$.

Besides NO, another important mediator of lesion caused by hypoxia is the intracellular calcium. This is responsible for the degradation of DNA during the I / $R$ event. Inhibition of phosphodiesterase-5 increases the concentration of guanosine cyclic monophosphate (cGMP) and causes a decrease in intracellular calcium, which would explain a protective effect of phosphodiesterase- 5 inhibitory medications during periods of ischemia ${ }^{5}$.

Tadalafil has a pharmacodynamics profile different from the other phosphodiesterase-5 inhibitor drugs, with a half-life approximately 4 times longer (17.5 hours), maintaining pharmacological action for up to 36 hours after ingestion ${ }^{6}$. The first experimental study with tadalafil in ischemia was performed in cardiomyocytes ${ }^{7}$, where the use of tadalafil prior to coronary occlusion in rats led to improved endothelial function and decreased ischemic area in myocardial infarction. In 2011, the first experimental study of the use of tadalafil in the kidney during ischemia was published, with a finding of a decrease in leukocyte infiltration in animals that used this medication ${ }^{8}$.

The present study analyzed the histological parameters in rat kidney tissue with the use of tadalafil during warm ischemia for 45 minutes and reperfusion for 24 hours.

\section{Methods}

This study was performed after approval by the Ethics Committee for the Use 
of Animals, Faculdade Evangélica do Paraná (protocol 2660/2014).

Twenty male Wistar rats (Rattus norvegicus albinus), heterogenic, aged between 3 and 4 months, weighing between 309 and 328 grams, were used. All animals were housed in individual polypropylene cages, with luminosity obeying the murine circadian cycle (12 hours of light and 12 hours of darkness). The animals were given drinking water and ration (Nuvilab CR1 ${ }^{\text {) }}$ ) with a free supply, without addition of protein, caloric or lipid supplement of any kind during the period of the research). Twelve hours before the procedure the animals were fasted. All the ethical principles of animal experimentation of the National Council of
Control of Animal Experimentation (CONCEA) were strictly respected.

The animals were randomly assigned to two groups of ten (Figure 1). The animals were anesthetized with a combination of ketamine hydrochloride (Ketalar ${ }^{\circ}$, Pfizer, São Paulo) at a dose of $90 \mathrm{mg} / \mathrm{kg}$ body weight, and xylazine hydrochloride (Rompum * Bayer, São Paulo) at a dose of $10 \mathrm{mg} / \mathrm{Kg}$ body weight, intraperitoneally in the left lower abdominal quadrant, with posterior abdominal trichotomy and immobilization with elastics on a surgical table, in position of dorsal decubitus. Antisepsis was performed with $10 \%$ polyvinylpyrrolidoneiodine solution and placement of sterile fenestrated operative field.

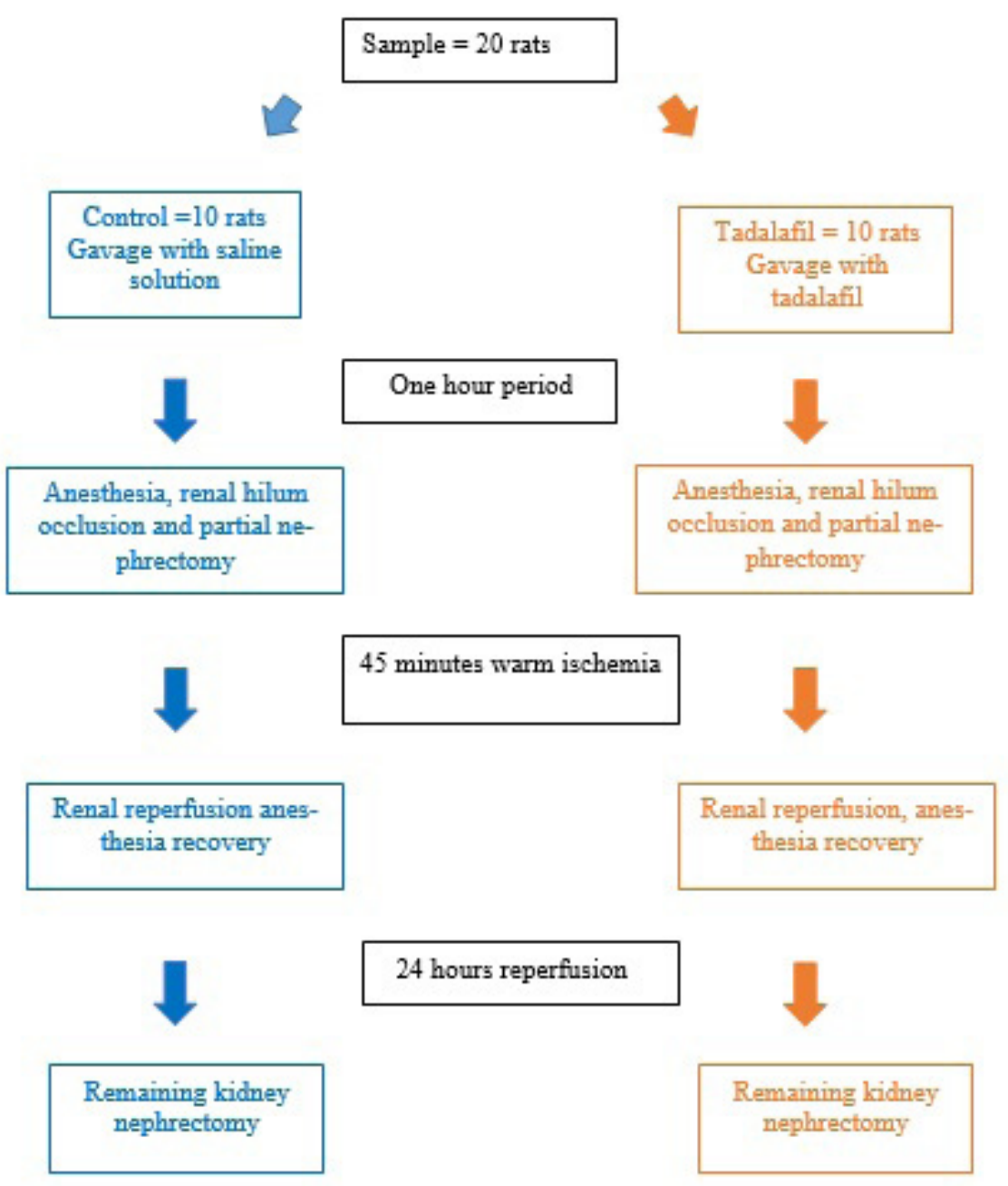

Figure 1 - Study design. 
In the control group, 1 ml of physiological saline was given per gavage one hour before the procedure. In the tadalafil group, tadalafil was administered at a concentration of $10 \mathrm{mg} /$ kg per gavage one hour before the procedure (Figure 2). The subsequent steps were the same for both groups, as follows: median laparotomy and abdominal wall opening by planes, medial retraction of the abdominal viscera with exposure of the left kidney and left renal pedicle, dissection of the left renal pedicle with en-block occlusion with a vascular micro clamp and then nephrectomy of the lower third of the left kidney. The lower pole of the kidney was removed and referred for pathological evaluation. Maintenance of the pedicle clamping of the left kidney (warm ischemia) for 45 minutes was achieved. After this period, renal blood flow was restored. Hemostasis with digital compression or with electrocautery in case of persistent bleeding was performed. Abdominal wall closure was done with continuous suture for both aponeurosis and skin with 3-0 nylon continuous suture.

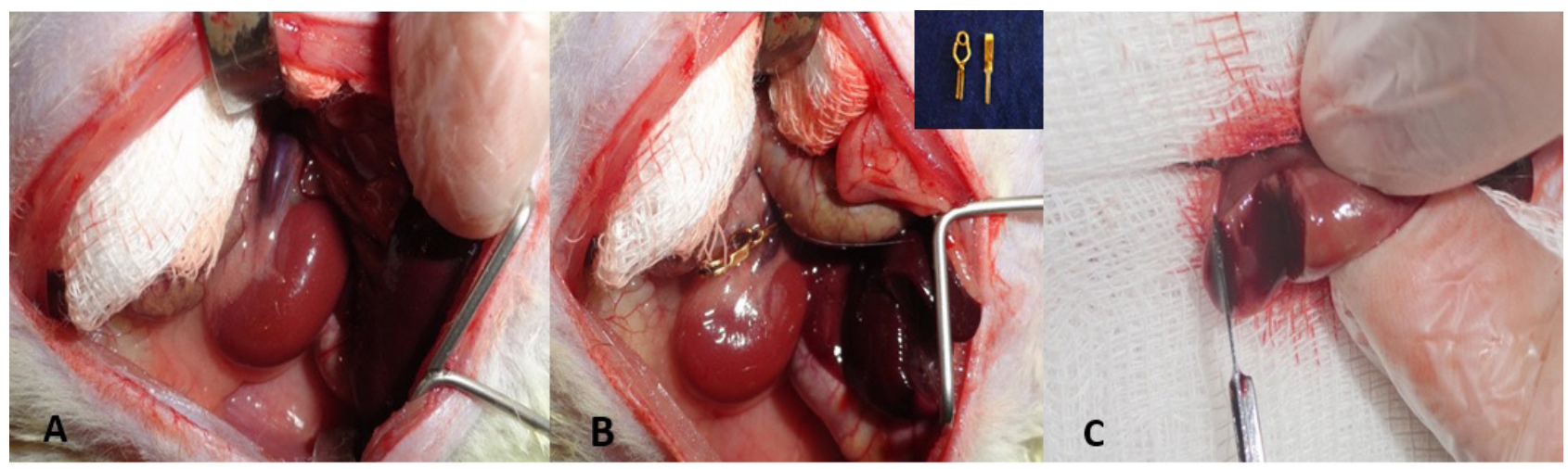

Figure 2 - Experimental process steps: A) Medium laparotomy with exposure of the left kid and renal pedicle; B) Warm ischemia with clamping of the renal pedicle with vascular microclamps; C) Partial nefrectomy: lower poly section of the kidney.

In the postoperative period, the rats received analgesic medication (tramadol at $15 \mathrm{mg} / \mathrm{kg}$ subcutaneously) for pain control, and it were kept in cages with a maximum of 4 animals per cage, being provided free supply of water and food.

After 24 hours of the initial procedure the animals were anesthetized again, as described above, and fixed in a surgical table. After abdominal antisepsis, a new median laparotomy was performed with removal of the remaining left kidney after ligation of the left renal artery and vein with 3-0 cotton thread. The removed kidney was fixed in $10 \%$ formalin solution. The euthanasia of the animals was performed with potassium chloride 19.1\%
$0.5 \mathrm{ml}$ intracardiacal at this same surgical procedure.

The $10 \%$ formalin-fixed kidney was subjected to washing, diaphanization, inclusion in paraffin and successive microtome cuts of $4 \mu \mathrm{m}$ thickness were performed (American Optical, Spencer AO 820). Subsequently, the slides were assembled for the execution of histochemical hematoxylin and eosin (HE) techniques.

The analysis and the pathological interpretation were performed by common optical microscopy using the Nikon Eclipse E400 microscope (Nikon, Tokyo, Japan), without previous knowledge of the groups being studied by the pathologist. Samples 
were examined at variable increases of 40 to 200 times.

The slides were placed for one minute in Harris hematoxylin solution. It was then washed in running water for 10 minutes. Subsequently, the slides were washed in distilled water twice consecutively and then impregnated with eosin-floxin for 45 seconds. This material was immediately rinsed with distilled water and then dewaxed, dehydrated and mounted.

The analyzed parameters described findings on light microscopy for renal tissue damage after $I / R^{9}$. The slides were marked only as group 1 and 2, with information being omitted where group 1 is the control group and group 2 is the tadalafil group. Eleven histological parameters were analyzed by the same pathologist:

1. Interstitial leukocyte accumulation
2. Detachment of basement membrane cells in the proximal tubule

3. Accumulation of desquamated cells in the proximal tubular lumen

4. Flattening and loss of brush border in the proximal tubules

5. Presence of tubular cylinders

6. Interstitial edema in proximal tubule cells

7. Capillary congestion in the proximal tubule

8. Cellular vacuolation in the proximal tubule

9. Dilatation of the lumen of the proximal tubule

10. Cell necrosis

11. Capillary tuft collapse

As previously described, in earlier studies, each histological parameter analyzed was classified into 6 sub-gradations (Chart 1) $)^{9,10}$.

Chart 1 - Classification system used for graduation of histological injury gravity in each histological parameter analyzed.

\begin{tabular}{|l|}
\hline GRADUATION OF THE HISTOLOGICAL GRAVITY OF INJURY \\
\hline Normal \\
\hline Focal areas injured \\
\hline Less than $10 \%$ of the injured area \\
\hline Ten to $25 \%$ of the injured area \\
\hline Twenty-five to $75 \%$ of the injured area \\
\hline More than $75 \%$ of the damaged cortical area \\
\hline
\end{tabular}

To describe the variables evaluated in the study, in relation to their histological patterns, the frequency and percentages of the scores of these variables were considered. The non-parametric Mann-Whitney test was used to compare the groups (control and tadalafil) in relation to the histological standard scores. $P$ values lower than 0.05 indicated statistical significance.

\section{Results}

There were no unexpected advents in the period of gavage, anesthesia, preparation and immobilization. The surgical procedure was performed successfully in all animals, without active bleeding after reperfusion period or intraoperative complications. Two rats from each group died during the postoperative recovery period and were excluded from the study. 
The mean weight of the animals in the control group was $322.6 \pm 5.1 \mathrm{~g}$, and in the tadalafil group $322.3 \pm 6.1 \mathrm{~g}$. No statistical difference was observed between groups $(p=$ 0.689) (Table 1).

Regarding to the analysis of the leukocyte accumulation in the kidney cortical interstitium the control group presented histological alterations in 5 of the 8 kidneys surveyed. Differently, in the tadalafil group, all the kidneys remained unchanged in the analyzed histological parameters, presenting a statistical difference between the control group and the tadalafil group $(p=0.036)$ (Figure 3$)$.

Table 1 - Microscopic analysis of leukocytes accumulation in the renal interstitium.

\begin{tabular}{|c|c|c|}
\hline HISTOLOGICAL PATTERN & $\frac{\text { CONTROL GROUP }}{\text { NUMBER OF ANIMALS }}$ & $\frac{\text { TADALAFIL GROUP }}{\text { NUMBER OF ANIMALS }}$ \\
\hline NORMAL & 3 & 8 \\
\hline FOCAL AREAS INJURED & 1 & 0 \\
\hline $\begin{array}{l}\text { LESS THAN } 10 \% \text { OF THE IN- } \\
\text { JURED AREA }\end{array}$ & 3 & 0 \\
\hline $\begin{array}{l}10 \text { TO } 25 \% \text { OF THE INJURED } \\
\text { AREA }\end{array}$ & 0 & 0 \\
\hline $\begin{array}{l}25 \text { TO } 75 \% \text { OF THE INJURED } \\
\text { AREA }\end{array}$ & 1 & 0 \\
\hline $\begin{array}{l}\text { MORE THAN } 75 \% \text { OF THE IN- } \\
\text { JURED AREA }\end{array}$ & 0 & 0 \\
\hline TOTAL & 8 & 8 \\
\hline
\end{tabular}

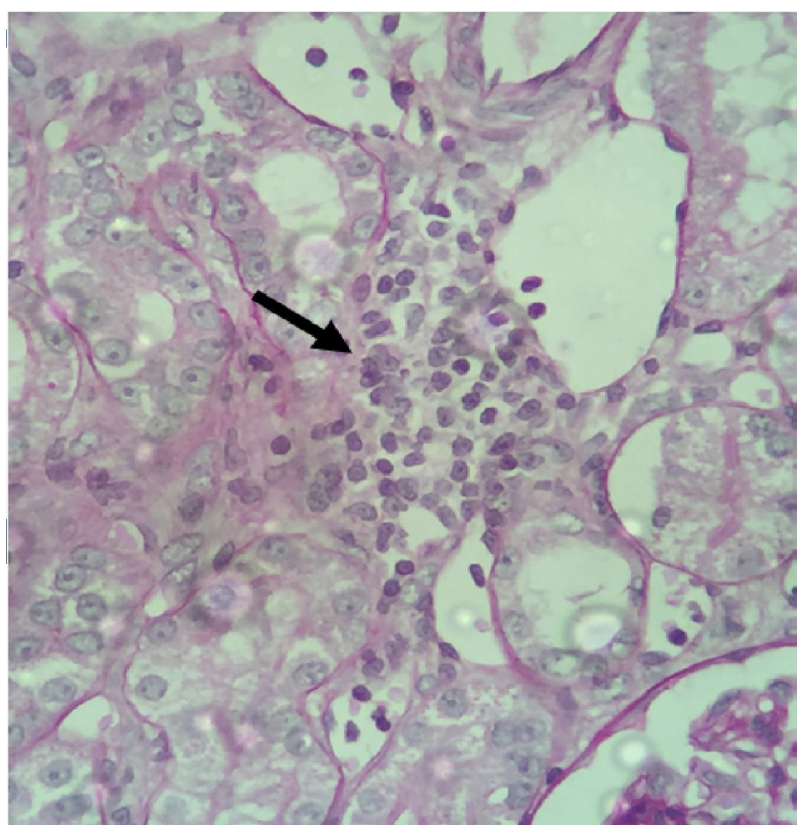

Figure 3 - Microfotography with hematoxylin and eosin coloring, demonstrating the presence of leukocyte infiltration in the renal interstitium (arrow) after
24 hours ischemia and reperfusion of the left kidney (optical microscope, x20 objective).

At the evaluation of the presence of tubular cylinders, six animals from the tadalafil group presented normal histology or only affected focal areas. This finding was in agreement with the control group where the majority of the animals had alterations of greater severity. However, our sample did not identify a statistical difference between the groups $(p=0.083)$ (Figure 4$)$. 


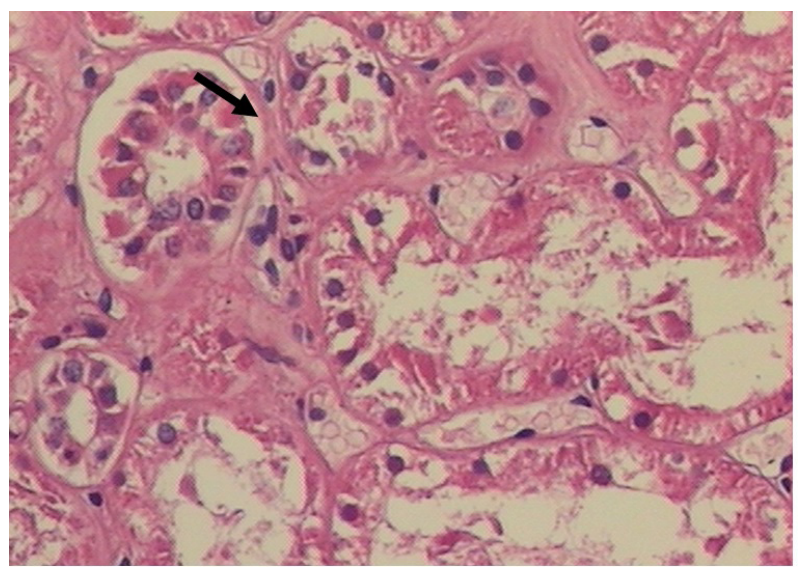

Figure 4 - Microfotography of blade with hematoxylin and eosin coloring, demonstrating tubular cells of the basal membrane (arrow) after ischemia and reperfusion of the left kidney (optical microscope, $x 20$ objective).
Microscopic analysis of the following items is summarized in Table 2. No statistical difference was identified between groups for the following evaluations: detachment of epithelial cells from the basal membrane of the proximal tubules ( $p=0.637)$, accumulation of desquamated cells within the proximal tubules ( $p=0.958)$, brush border loss in the proximal tubules ( $p=0.753)$, presence of interstitial edema ( $p=0.916)$, presence of capillary congestion $(p=0.128)$, presence of cell vacuolation ( $p=0.248$ ), proximal tubule light dilation ), presence of cell necrosis ( $p=$ $0.564)$ and presence of capillary tuft collapse $(p=0.401)$.

Table 2 - Statistical analysis of the histological variables analyzed during the study.

\begin{tabular}{|l|l|}
\hline Histological variables & p-value \\
\hline Interstitial leukocyte accumulation & 0,036 \\
\hline Detachment of basement membrane cells in the proximal tubule & 0,637 \\
\hline $\begin{array}{l}\text { Accumulation of desquamated cells in the proximal tubular } \\
\text { lumen }\end{array}$ & 0,958 \\
\hline Scaling and loss of the brush border in the proximal tubules & 0,753 \\
\hline Presence of tubular cylinders & 0,083 \\
\hline Interstitial edema in proximal tubule cells & 0,916 \\
\hline Capillary congestion in the proximal tubule & 0,128 \\
\hline Cellular vacuolization in the proximal tubule & 0,248 \\
\hline Dilation of the proximal tubule lumen & 0,093 \\
\hline Cell necrosis & 0,564 \\
\hline Capillary tuft collapse & 0,401 \\
\hline
\end{tabular}

\section{- Discussion}

Renal damage during ischemia occurs mainly in the renal tubules, involving varied and complex mechanisms, and is directly related to the time elapsed after the interruption of oxygenation. Ischemia triggers a cascade of events such as vasoconstriction, endothelial 
cell activation, tubular edema, tubular epithelial cell necrosis, interstitial edema, calcium cell inflow, and adenosine triphosphate (ATP) depletion. Even after restoration of blood flow, with consequently oxygen supply to the tissue, injury to the renal cells proceeds and is amplified by the expression of endothelial adhesion molecules, which promote leukocyte activation and increase of active oxygen species, mitochondrial dysfunction and migration Leukocytes to the interstitium ${ }^{11}$.

The renal reperfusion process after period of hypoxia plays an important role in the establishment of the lesion by the activation of the inflammatory response. Impaired proximal and endothelial tubular cells trigger the inflammatory process by releasing cytokines and chemokines, leading to local infiltration by inflammatory cells. Inflammation of inflammatory cells, edema, presence of intratubular cylinders, brush border integrity, and necrosis, among others, are histological markers of acute renal ischemic injury ${ }^{12}$.

The understanding of this mechanism leads one to believe that the control of the inflammatory response may be associated with injury reduction by $I \backslash R$. Thus, the use of substances that act in this cycle can improve the outcome of the patient.

One class of medication previously evaluated in myocardial and renal ischemia is phosphodiesterase-5 inhibitors. Inhibition of this enzyme ultimately leads to the maintenance of lower levels of intracellular calcium, with smooth muscle relaxation and vasodilation. Drugs such as sildenafil, vardenafil and tadalafil, have been widely used in humans for the treatment of erectile dysfunction since $1998^{13}$.

Sildenafil, which has a half-life of approximately 4 hours, was the first phosphodiesterase-5 inhibitor to be evaluated as a protector during renal ischemia, demonstrating improvement after warm renal ischemia in renal pig transplants ${ }^{14}$.
New inhibitors of phosphodiesterase- 5 (I5FE), such as vardenafil and tadalafil, were developed and approved for the treatment of erectile dysfunction in 2003. In renal ischemia, vardenafil demonstrated improved histological parameters and apoptosis in kidneys which underwent to 24-hour ischemia Reperfusion ${ }^{15}$.

Tadalafil has a pharmacodynamics profile different from the other I5FE, with a half-life approximately 4 times longer (17.5 hours), maintaining action for up to 36 hours $^{6}$. Although one of the studies evaluated has used tadalafil intraperitoneally, the drug is available for oral use and has absorption and effectiveness proven by this route of administration. Therefore, its administration by gavage in this experiment was chosen.

The rat was chosen for its availability, affordability and easy handling. The size of the sample was defined based on studies already done to evaluate tadalafil in renal ischemia, with the aim of using as few animals as possible to demonstrate significant histological changes $^{16}$.

We chose not to perform direct nephrectomy in this experiment, in order to reduce the trauma to the animal, since the side does not interfere with the final results ${ }^{17}$.

The defined time of warm ischemia was based on previous studies ${ }^{9}$, where the majority used 45 or 60 minutes. The use of the 24-hour reperfusion period for analysis of histological changes was defined based on analysis of studies that identified significant alterations after 24 hours of renal blood flow restoration ${ }^{9,10}$.

As previously described, infiltration of inflammatory cells into the renal tubules is one of the histological markers of acute renal ischemic injury ${ }^{12}$. The present study showed less infiltration of leukocytes in the renal interstitial of the animals belonging to the tadalafil group. This difference was statistically significant when compared to the control group $(p=0.036)$. 
Although the presence of leukocytes is part of the natural history of the ischemia and reperfusion process, its role in producing injury or repair, or both, remains undefined. Leukocytes may play an important role in the mechanism of parenchymal injury after ischemia-reperfusion, as well as in the regeneration process, but their exact role still needs to be clarified ${ }^{1}$. In the present study, the repair role or leukocyte damage was not included as part of the initial goal of the study. Its finding represents less local inflammation with tadalafil. However, for better definition, specific studies for leukocyte evaluation would be necessary, and the data presented here serve as a basis for future research. The finding of leukocyte infiltration observed is consistent with most of the studies performed with tadalafil in kidney ischemia.

Five of eleven articles published since 2011 with the use of tadalafil during kidney ischemia demonstrated less leukocyte infiltration with medication. Two of eleven did not report alteration and four did not evaluate this parameter (Table 3). The differences in the results probably occur because of sample size, time of ischemia and reperfusion variables or changes in dose and route of administration of the medication.

Table 3 - Experimental studies done with use of tadalafil in ischemia and renal reperfusion.

\begin{tabular}{|c|c|c|c|c|c|c|}
\hline & $\begin{array}{l}\text { Animals } \\
\text { group }\end{array}$ & $\begin{array}{l}\text { JLeucocyte } \\
\text { Infiltration }\end{array}$ & $\begin{array}{l}\text { Other parameters } \\
\text { Compared to } \\
\text { tadalafil group }\end{array}$ & $\begin{array}{l}\text { Ischemia } \\
\text { period }\end{array}$ & $\begin{array}{l}\text { Reperfusion } \\
\text { Period }\end{array}$ & $\begin{array}{l}\text { Tadalafil } \\
\text { Dose }\end{array}$ \\
\hline GUZELOGLU et al. (2011) & 7 & Less & Unchanged & $60 \mathrm{~min}$ & $60 \mathrm{~min}$ & $10 \mathrm{mg} / \mathrm{kg}$ \\
\hline GASANOV et al. (2011) & 6 & Unchanged & Less Necrosis & $45 \mathrm{~min}$ & $60 \mathrm{~min}$ & $1 \mathrm{mg} / \mathrm{kg}$ \\
\hline FADEGGON et al. (2011) & 5 & N/A & $\begin{array}{l}\text { Creatinine after } \\
\text { ischemia - } \\
\text { Unchanged }\end{array}$ & $90 \mathrm{~min}$ & $\begin{array}{l}1,3 \text { and } 7 \\
\text { days }\end{array}$ & $\begin{array}{l}40 \mathrm{mg} / \\
\text { animal } \\
\text { (pigs) }\end{array}$ \\
\hline KUÇUK et al. (2012) & 20 & Less & $\begin{array}{l}\text { Less edema/ } \\
\text { dilation tubular }\end{array}$ & $60 \mathrm{~min}$ & $90 \mathrm{~min}$ & $1 \mathrm{mg} / \mathrm{kg}$ \\
\hline MORALES et al. (2013) & 6 & Less & Less vacuolation & $60 \mathrm{~min}$ & 7 days & $20 \mathrm{mg} / \mathrm{kg}$ \\
\hline SOHOTNIK et al. (2013) & 10 & Less & $\begin{array}{l}\text { Less necrosis/ } \\
\text { cylinders/ capillary } \\
\text { congestion }\end{array}$ & $45 \mathrm{~min}$ & $\begin{array}{l}60 \text { to } 240 \\
\min \end{array}$ & $10 \mathrm{mg} / \mathrm{kg}$ \\
\hline ALFARANO et al. (2014) & 10 & Unchanged & Unchanged & $45 \mathrm{~min}$ & 24 hours & $10 \mathrm{mg} / \mathrm{kg}$ \\
\hline EROL et al. (2015) & 7 & N/A & $\begin{array}{l}\text { Less alteration in } \\
\text { all parameters }\end{array}$ & $60 \mathrm{~min}$ & $60 \mathrm{~min}$ & $10 \mathrm{mg} / \mathrm{kg}$ \\
\hline CARVALHO et al. (2015) & 6 & N/A & $\begin{array}{l}\text { Urea / creatinine / } \\
\text { cytokines }\end{array}$ & $30 \mathrm{~min}$ & 24 hours & $10 \mathrm{mg} / \mathrm{kg}$ \\
\hline AMASYALI et al. (2015) & 8 & Less & $\begin{array}{l}\text { Dilatation and } \\
\text { tubular degenera- } \\
\text { tion / vacuolization } \\
\text { / necrosis }\end{array}$ & $60 \mathrm{~min}$ & $60 \mathrm{~min}$ & $10 \mathrm{mg} / \mathrm{kg}$ \\
\hline MEDEIROS et al. (2017) & 6 & N/A & $\begin{array}{l}\text { TNFa, IL1b, IL6. } \\
\text { Creatinine, Urea, } \\
\text { C-reactive protein }\end{array}$ & $45 \mathrm{~min}$ & 8 hours & $10 \mathrm{mg} / \mathrm{kg}$ \\
\hline
\end{tabular}

N / A: Not analyzed; TNF: Tumor necrosis factor, IL: Interleukin 
Another histological variable suggestive of renal damage is the presence of tubular cylinders, which are the result of epithelial cell desquamation caused by local ischemia, in association with stasis within the proximal tubules, as a consequence of a decrease in glomerular filtration rate. In the present study, a considerable numerical difference occurred, where microscopic analysis exhibited the majority of animals with normal renal tissue or focal areas affected in the tadalafil group, differing from the control group where the majority of the animals presented changes of greater severity. Although it may suggest a trend of improvement with the use of tadalafil, the statistical analysis showed no difference ( $p$ $=0.083$ ). The use of a larger sample could be necessary to clarify the alteration observed in this specific histological parameter.

It was not possible to conclude from the study whether the lower infiltration of leukocytes in the observed interstitium represents, in fact, an effective protection against the deleterious effects of kidney ischemia and reperfusion. The use of less comprehensive classifications of tissue injury severity, as well as a greater number of samples, would be alternatives to demonstrate greater statistical strength in some histological parameters analyzed which did not present statistical significance.

The present study was a preliminary evaluation, assuming that this medication has a histological effect on the renal tissue during the ischemic process, opening the perspective of continuing the evaluation of renal ischemia. The action of tadalafil in the cascade involving nitric oxide allows future research with markers of oxidative stress, in addition to other inflammatory markers. Since tadalafil is a widely used drug in humans, its study in partial nephrectomies, where ischemia time is a key factor for recovery of renal function, may be a future prospect of easy access and low cost.
Finally, in addition to the specific surgical protection from a partial nephrectomy, nephroprotective research should be stimulated, since a wide range of clinical conditions leads to renal ischemia, either by hypo perfusion or by the use of nephrotoxic drugs, aiming to reduce the incidence of renal failure and mortality.

\section{Conclusions}

The analysis of the histological parameters in rat kidney tissue when using tadalafil during warm ischemia for 45 minutes and reperfusion for 24 hours leads to the conclusion that there was a statistically significant decrease of leukocyte infiltration in the renal interstitium. No other histological changes were identified at this study.

\section{References}

1- Carvalho ALSL, Araújo NAB, Lima RH, Menezes RRB, Medeiros PJ, Medeiros AC. Tadalafil and its effects in renal function after kidney ischemia and reperfusion in rats. J Surg Clin Res. 2015;6 (1):22-30. doi: 10.20398/jscr.v6i1.8193.

2- Volpe A, Blute ML, Ficarra V, Gill IS, Kutikov A, Porpiglia F, Rogers C, Touijer KA, Poppel HV, Thompson R. Renal ischemia and function after partial nephrectomy: a collaborative review of the literature. Eur Urol. 2015;68(1):61-74. doi: 10.1016/j. eururo.2015.01.025.

3- Corbin JD. Mechanisms of action of PDE5 inhibition in erectile dysfunction. Int $\mathrm{J}$ Impot Res. 2004;16 (1):4-7. doi: 10.1038/ sj.ijir.3901205.

4- Verit A, Savas $M$, Ciftci $H$, Aksoy N, Taskin A, Topal U. Assessment of the acute effects of tadalafil on the cardiovascular system based on examination of serum oxidative status and paraoxonase activity in men with erectile dysfunction: a preliminary study. Int J Impot Res. 2009 Oct;22(2):115-9. doi: 10.1038/ijir.2009.58.

5- Coward R, Carson C. Tadalafil in the treatment of erectile dysfunction. Ther 
Clin Risk Manag. 2008;4(6):1315-29. doi: 10.2147/tcrm.s3336.

6- Porst H, Padma-Nathan H, Giuliano F, Anglin G, Varanese L, Rosen R. Efficacy of tadalafil for the treatment of erectile dysfunction at 24 and 36 hours after dosing: a randomized controlled trial. Urology. 2003;62(1):121-5. doi: 10.1016/S0090-4295(03)00359-5.

7- Sesti C, Florio V, Johnson EG, Kloner RA. The phosphodiesterase-5 inhibitor tadalafil reduces myocardial infarct size. Int J Impot Res. 2006;19(1):55-61. doi: 10.1038/ sj.ijir.3901497.

8- Guzeloglu M, Yalcinkaya F, Atmaca S, Bagriyanik A, Oktar S, Yuksel O, Fansa I, Hazan E. The beneficial effects of tadalafil on renal ischemia-reperfusion injury in rats. Urologia Int. 2011;86(2):197-203. doi: 10.1159/000321927.

9- Jablonski P, Howden BO, Rae DA, Birrell CS, Marshall VC, Tange J. An experimental model for assessment of renal recovery from warm ischemia. Transplantation. 1983;35(3):198204. doi: 10.1097/00007890-19830300000002.

10-Goujon J, Hauet T, Menet E, Levillain P, Babin P, Carretier M. Histological evaluation of proximal tubule cell injury in isolated perfused pig kidneys exposed to cold ischemia. J Surg Res. 1999;82(2):228-33. doi: 10.1006/jsre.1998.5526.

11-Basile DP, Anderson MD, Sutton TA. Pathophysiology of acute kidney injury. Compr Physiol. 2012; 2(2):1303-53. doi: 10.1002/cphy.c110041.

12-Paller MS, Hoidal JR, Ferris TF. Oxygen free radicals in ischemic acute renal failure in the rat. J Clin Invest. 1984 Jan;74(4):1156-64. doi: $10.1172 /$ jci111524.

13-Shamloul R, Ghanem H. Erectile dysfunction. Lancet. 2013;381(9861):153-65. doi: 10.1016/s0140-6736(12)60520-0.

14-Lledo-Garcia E, Rodriguez-Martinez D, Cabello-Benavente $R$, Moncada-Iribarren I, Tejedor-Jorge A, Dulin E, HernandezFernandez C, Canizo-Lopez JF. Sildenafil improves immediate posttransplant parameters in warm-ischemic kidney transplants: experimental study. Transpl Proc. 2007;39(5):1354-6. doi: 10.1016/j. transproceed.2007.01.082.

15-Sousa RCD, Neto AAM, Capelozzi VL, Absaber AM, Rodrigues OR. Effects of vardenafil on the kidney of Wistar rats submitted to acute ischemia and reperfusion. Acta Cir Bras. 2015;30(5):339-44. doi: 10.1590/s0102865020150050000005.

16-Fagundes DJ, Taha MO. Modelo animal de doença: critérios de escolha e espécies de animais de uso corrente. Acta Cir Bras. 2004;19(1):59-65. doi: 10.1590/s010286502004000100010.

17-Rhoden ELCBCC, Rhoden CR, Lucas ML, Pereira-Lima L, Zettler C, Belló-Klein A. The role of nitric oxide pathway in the renal ischemia-reperfusion injury in rats. Transpl Immunol. 2002;10(4):277-84. doi: 10.1016/ s0966-3274(02)00079-5.

18-Medeiros VFLP, Azevedo ÍM, Carvalho MDF, Oliveira CN, Egito ESTD, Medeiros AC. The renoprotective effect of oral tadalafil pretreatment on ischemia/reperfusion injury in rats. Acta Cir Bras. 2017;32(2):907. doi:10.1590/s0102-865020170201.

\section{Correspondence:}

Eduardo Gabriel Geber Wietziekoski

Rua Portugal, 329

80510-280 Curitiba - PR Brasil

eduardoggw@gmail.com

Received: July 02, 2017

Review: Sept 05, 2017

Accepted: Oct 08, 2017
Conflict of interest: none

Financial source: none

${ }^{1}$ Research performed at Medical Research Institute, Faculdade Evangélica do Paraná (FEPAR), Curitiba-PR, Brazil. Part of Master degree thesis, Postgraduate Program in Surgery Principles. Tutor: Prof. Dr. Nicolau Gregori Czeczko. 